Imágenes biomédicas

\title{
Herpesviridae: Citomegalovirus. Caso clínico pediátrico
}

\author{
Pinto, Rolando J.; Sarli, Diana; Sassari Sandoval Marilina G.; Valdovinos Zaputovich \\ Bertha M
}

El Citomegalovirus (CMV) tiene ADN de doble cadena, es miembro de la familia de los Herpesvirus, posee un ciclo reproductivo lento y su transmisión es a través de saliva, contacto sexual, transferencia placentaria, lactancia materna, transfusión sanguínea o trasplante de médula ósea/órganos sólidos ${ }^{(1)}$. La infección primaria se produce por transmisión vertical o en un paciente previamente seronegativo, quedando latente a lo largo de la vida del huésped, siendo las células de la línea mieloide su principal reservorio ${ }^{(1,2)}$ En pacientes inmunocomprometidos la respuesta inmune inicial que restringe la replicación del virus después de una reactivación está ausente o muy disminuida, por lo que el huésped puede desarrollar una enfermedad sistémica, que comprometa determinados órganos (ojos, tracto gastrointestinal, cerebro, suprarrenales y pulmón) $)^{(1,2)}$. Con respecto a este último órgano, el CMV es causa importante de Neumonía Intersticial oportunista en la población pediátrica e inmunocomprometidos, la cual es una entidad de difícil diagnóstico por diferentes causas como lo son: curso subclínico, enfermedad terminal o diseminación terminal con muchos órganos afectados que pueden llegar a ser fulminante al interaccionar con infecciones concomitantes, requiriéndose un alto índice de sospecha que permita la implementación de terapias adecuadas ${ }^{(1,2)}$.

El diagnóstico de Neumonía por CMV se realiza mediante la identificación de signos y síntomas clínicos de infección pulmonar, en combinación con los hallazgos en cultivo o recuento viral por detección de ADN-CMV por PCR en fluido de lavado broncoalveolar o esputo. Los diagnósticos diferenciales clínicos dependen del grupo etario afectado y el estado inmunológico. En pediatría son importantes los virus influenza y adenovirus ${ }^{(2,3,4)}$.

La infección activa se puede diagnosticar utilizando tinciones como Hematoxilina-Eosina, Giemsa, Wrigth o Papanicolau, demostrando cambios característicos morfológicos de agrandamiento de las células infectadas (efecto citomegálico) e inclusiones basofílicas intranucleares rodeadas por un halo claro dando el aspecto de "ojo de búho" e inclusiones eosinofílicas en el citoplasma ${ }^{(1,2,3)}$.

Caso clínico: PL. HC: 161402. Niña de un año, oriunda del interior de la provincia de Corrientes, queconsulta el 28 de abril de 2015 al Hospital Pediátrico "Juan Pablo II" por vómito, hipertermia y agitación progresiva de diecisiete días de evolución, que no responde a terapia antibiótica previa. Estudios complementarios: Rx de tórax se observa neumonía bullosa, el analítico clínico presenta leucocitosis, eritrosedimentación acelerada y HTO de 30\%, decidiéndose internación en clínica médica con diagnóstico de neumonía bullosa y anemia leve. Se realiza lobectomía de lóbulo superior derecho y decorticación, obteniéndose muestras para estudio anatomopatológico.

Por mala evolución clínica, la paciente es trasladada a UCIP, continuando clínica y hemodinamicamente lábil, potencialmente descompensable, con saturación de 02 por debajo de $90 \%$, en ARM modalidad VAFO. Óbito. 


\section{tonsosen

Diagnóstico histopatológico: compromiso de vías aéreas y parénquima pulmonar representada por neumonía intersticial y lesión alveolar difusa (Fotos 1).

\section{Foto 1}

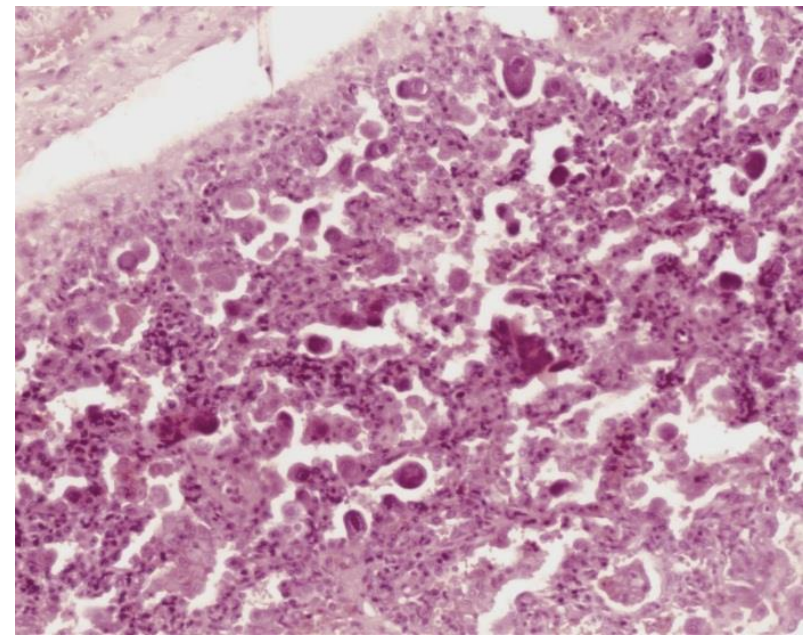

Foto 1: Caso clínico: PL. HC: 161402 B 2017365 Hematoxilina-Eosina: compromiso de vías aéreas y parénquima pulmonar representada por neumonía intersticial y lesión alveolar difusa.

La infección viral por CMV se observa afectando el epitelio alveolar (Foto 2),el cual está revestidos por células tipo II que se han regenerado para cubrir el defecto epitelial dejado por la necrosis de las células tipo I; las células infectadas son grandes (citomegalia) y presentan inclusión azul oscura en el núcleo, en otras se observa material basofílico nuclear, grumos de material basófilo a lo largo del envoltorio nuclear (cuerpos orbitales) e inclusiones basofílicas en citoplasma (Foto 3); acompañada por un infiltrado mononuclear intersticial predominantemente linfocitario.

\section{Foto 2}

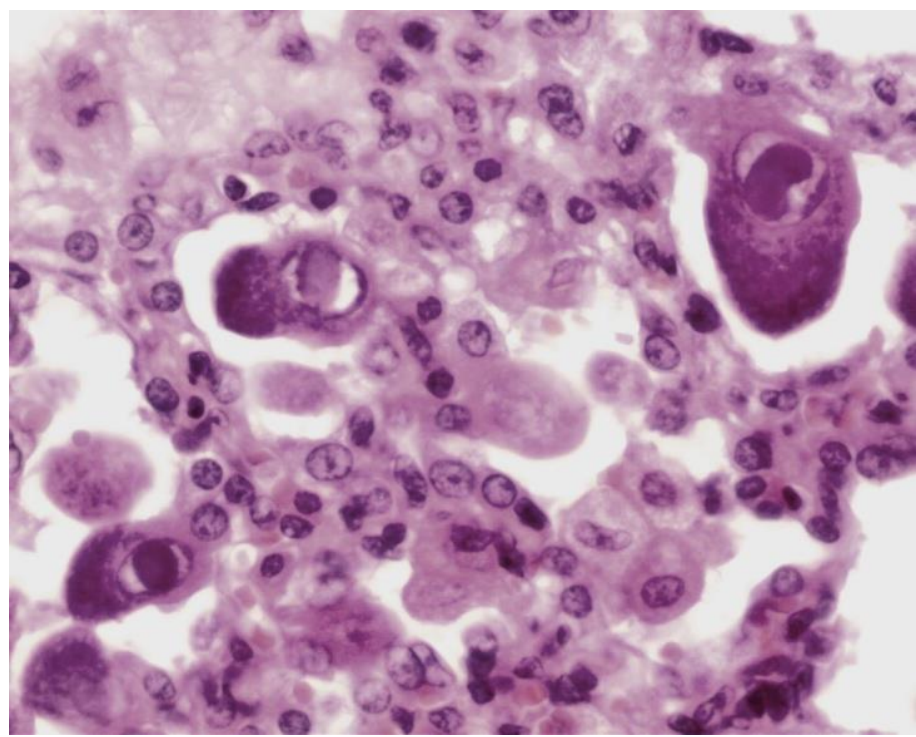




\section{Denowir

Foto 3

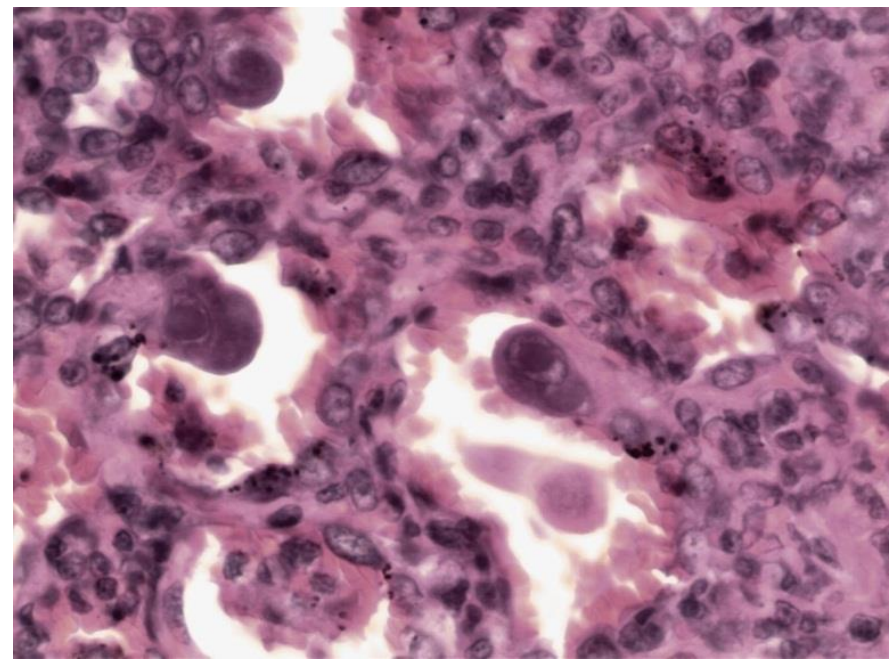

Foto 2 y 3: Caso clínico: PL. HC: 161402 B 2017365 Hematoxilina-Eosina.Epitelio alveolar revestido por células tipo II que se han regenerado para cubrir el defecto epitelial dejado por la necrosis de las células tipo I. Se aprecian las células infectadas con citomegalia y la presencia de inclusión azul oscura en el núcleo, en otras se observa material basofílico nuclear, cuerpos orbitales e inclusiones basofílicas en citoplasma

\section{BIBLIOGRAFÍA}

1. Santos González Mónica P. Caracterización de la Neumonía por Citomegalovirus en pacientes pediátricos captados en hospitales de la misericordia 2010-2014. Universidad Nacional de Colombia. Facultad de Medicina. Departamento de Pediatría. Bogotá D.C., Colombia. 2014.

2. Cabrera Valdés F.; Gómez Fonseca C.; Capó de la Paz Virginia; González Bosch L. y cols. Infección por citomegalovirus en paceintes VIH/sida. Revista cubana de Hemtol, Inmunol y Hemoter. 2015; 31 (2):113126

3. William M.;Thurlberk; Miller Roberta R. El aparato respiratorio. Rubin E.; FarberJhon L. y cols. Patología. Segunda Edición. Editorial Médica Panamericana. 1990; 508-509.

4. LackErnest E.; Chandler Francis W.; Pearson Gary R. CytomegalovirusInfection. ConnorCaniel H.; Chandler Francis W. 91-99

\section{Datos de Autor}

\section{Titulo:}

Herpesviridae: Citomegalovirus. Caso clínico pediátrico

\section{Autores:}

Pinto, Rolando J. (2)

Sarli, Diana ${ }^{(1-2)}$

Sassari Sandoval Marilina G. ${ }^{(1-2)}$

Valdovinos Zaputovich Bertha $\mathrm{M}^{(1-2)}$

Lugar de Trabajo: 1- Hospital Pediátrico Juan Pablo II. 2- Facultad Medicina UNNE. 